\title{
Serras, serrotes e limas: apontamentos sobre a tecnologia e o design na luteria de guitarras
}

Saws and files: notes on technology and design in electric guitar lutherie

PEREIRA, Rodrigo; Doutorando; UFPR - Universidade Federal do Paraná

rodmateus@hotmail.com

CORRÊA, Ronaldo; Doutor; UFPR - Universidade Federal do Paraná

rcorrea@ufpr.br

\section{Resumo}

Pouco é obtido sobre a luteria no Brasil quando se pesquisa em livros, ainda mais quando se busca pensar a atividade como trabalho e sua tecnologia. Através das narrativas dos construtores de guitarra elétrica no país nos anos 1960 e 1970, obtidas por meio de entrevistas, este texto tem por objetivo ilustrar e discutir como desenvolviam seus métodos de produção, que os permitiam se manter inseridos nessa indústria tão específica e singular e, além disso, evidenciar como integraram uma tecnologia particular, mas que ao menos é tempo genérica, quando adapta e se apropria de conhecimentos de diversas áreas, diretamente atreladas ao processo do Design (de projetar e produzir). Os fatos mostrados esboçam a necessidade de se pesquisar e descrever tecnologias específicas, bem como documentar trajetórias biográficas e laborais dos sujeitos envolvidos nestes processos.

Palavras Chave: tecnologia; design; cultura material e luteria.

\begin{abstract}
There are a few documentation about lutherie in Brazil when researching in books, especially when in searching to think that work as labor and its technology. Through the narratives of electric guitar builders between 1960s and 1970s, obtained through interviews, this text aims to illustrate and discuss how they developed their methods of production, which allowed them to remain working in this specific and unique industry, and to show how they have integrated a particular technology, but generic at the same time, when it adapts and appropriates knowledge of several areas, directly linked to the design process. The facts shown outline the need to research and describe specific technologies, as well as document biographical and labor trajectories of the subjects involved in these processes.
\end{abstract}

Keywords: technology; design; material culture and lutherie. 


\section{Introdução}

A construção de instrumentos musicais manualmente remonta há milênios, desde o momento no qual foi percebida a possibilidade desta produção podendo "ser detectada há dezenas de milhares de anos a partir da elaboração de apitos e monódicos feitos de ossos de rena e flautas mais sofisticadas feitas de ossos de pássaros" (ROQUE, 2003, p.11), mas não dispõe de uma única história, tampouco de datação clara sobre seu início. Sendo o termo luteria derivado da palavra luth (alaúde ${ }^{1}$ em francês), o que se assume comumente é considerar a história do ofício na Europa, a partir da idade média (séculos $\mathrm{V}$ ao XV), com a adaptação do $A l^{\prime} u d$ árabe para o alaúde europeu, sendo este o primeiro instrumento de cordas com caixa de ressonância do continente (ALMEIDA e PIRES, 2012 e ROQUE, 2003).

O conjunto de técnicas desenvolvidas na construção de alaúdes se manteve por muitos anos e se adequou (ou foi adequado) para a construção de outros instrumentos, como vieles, vihuelas, violas da gamba, liras e, no século XVI, para construção de violinos, bem como nos séculos seguintes pela construção de violões (séculos XVII a XIX). Um dos momentos mais recentes desta história se deu pela invenção da guitarra elétrica, que é um produto da primeira metade do século XX. A guitarra elétrica teve seu início na eletrificação de violões e em seguida adquiriu sua forma atual, com corpo sólido e captação magnética².

No Brasil, a luteria de guitarras elétricas, de acordo com Caesar (1999) tem início no final dos anos 1950, quando construtores de violão e fábricas de instrumentos de cordas desenvolvem seus primeiros experimentos, sendo ponderado por este autor que Vitório Quitillio, então funcionário da empresa Del Vecchio, foi o precursor desta movimentação no país. Esse começo da atividade no Brasil se dá cerca de dez anos após a invenção da guitarra elétrica, atribuída aos Estados Unidos da América na década de 1940 (EVANS, 1977).

No advento da criação do instrumento, os norte-americanos alcançaram sucesso comercial com a guitarra elétrica através dá produção em série, utilizando de maquinário e divisão de trabalho, impulsionados pela propagação do gênero musical rock n'roll, do qual a guitarra se tornaria símbolo (WAKSMAN, 2001). No Brasil, a atividade se inicia pelo trabalho estritamente artesanal, considerado aqui como um processo produtivo onde há o domínio do artesão em todas as fases da produção, da obtenção de matéria-prima, desenvolvimento de técnicas de produção e de trabalho, até a comercialização do produto (FRANÇA, 2005). Como considera Adão Martins, um construtor de guitarras da época, esse início é dependente do trabalho e ferramentas manuais: “...nós compramos um serrote, uma serra, uma lima. E fizemos lá... produzir nos fundos. Vamos fabricar ((guitarras)). Isso em 1958" (MARTINS, 2013).

O "criar" e o "fazer" na luteria da guitarra elétrica materializam o trabalho do construtor, bem como fornecem indícios do desenvolvimento de sua tecnologia construtiva atrelados a características do Design, enquanto atividade inata do ser humano, e que se encadeia pela geração de projetos, esboços e modelos (CARDOSO, 2011 e FORTY, 2007). Como fragmento da dissertação de mestrado do coautor ${ }^{3}$, se objetiva aqui exemplificar e discutir o desenvolvimento

\footnotetext{
${ }^{1}$ Instrumento de cordas utilizado no começo do segundo milênio, descendente do árabe Oud, do qual herda seu formato piriforme.

${ }^{2}$ Dispositivo magnético que capta o movimento (vibração) das cordas metálicas, gerando um sinal elétrico que é posteriormente convertido em ondas sonoras pelo amplificador.

${ }^{3}$ PEREIRA, Rodrigo Mateus. Construção e Design de Guitarras nos anos 1960 e 1970: Narrativas sobre Trabalho e
} 
técnico e tecnológico exercido pelos construtores de guitarra no Brasil, no recorte temporal e espacial de 1960 e 1970 em São Paulo - SP e Porto Alegre - RS. Pelo fato da bibliografia disponível ser insuficiente sobre o tema, sendo ainda mais escassa quando se busca pensar a atividade como profissão, como escolha de vida e como um sistema de desenvolvimento de habilidades e técnicas específicas, a dissertação foi embasada nas trajetórias dos construtores narradas por eles mesmos, através de entrevistas com quatro luthiers ${ }^{4}$ da época, material este que apóia também este texto. Em seus discursos, os entrevistados, a saber os paulistas Romeu Benvenuti, Sebastião da Silva e Alaor Rangon; e Adão Martins, de Porto Alegre, deixam evidentes suas técnicas e de que forma desenvolveram tecnologia própria, aparente aqui quando tratadas pelos exemplos técnicos do trabalho que exerciam. Suas trajetórias laborais descrevem uma atividade que se inicia de modo empírico e labor exclusivamente manual e, aos poucos, se torna mais autônoma e mecanizada.

Assim, como forma de se pensar a luteria, especificamente de guitarras elétricas, como atividade, se escolheu aqui reconstruir, através do discurso dos construtores, algumas técnicas utilizadas, bem como ponderar sobre seu desenvolvimento técnico e processual, no ambiente dos anos 1960 e 1970. Evidencia-se que a projetação e produção de artefatos (de máquinas ou de produtos) nunca se descolou do cotidiano desses trabalhadores em seu período de constituição.

\section{Luteria de Guitarra e Design}

Um dos precursores da construção de guitarras elétricas, o norte-americano Leo Fender (1909-1991) não era músico, guitarrista ou luthier. No entanto, foi um autodidata em Design. Claramente Leo Fender não foi um designer no sentido mais comum da palavra, quando atribuído ao profissional do Design, mas nos apoiamos em Willem (1990), Forty (2007) e Cardoso (2011) para considerá-lo praticante (ou executor) do Design quando exerceu e realizou, na produção de guitarras, elementos comuns de projetos desta disciplina.

Forty (2007) e Cardoso (2011) sugerem a associação do Design à produção a partir de alguns processos no sistema de fábrica, momento no qual o designer passa a ter função primordial no projeto e fabricação, e quando um Design adequado pode significar o sucesso ou o fracasso de se produzir em série. Forty (2007) se utiliza do termo como a preparação para a produção de bens manufaturados. Na história dos processos de industrialização no ocidente, em especial na Europa, a figura do designer começa a ganhar importância com o início da produção seriada, pois a etapa de projetação passa a ser individualizada. Projetos e processos específicos são essenciais para manufatura, como forma de padronização no máximo nível possível (Forty, 2007).

Para Forty (2007) o grande crescimento do mercado de bens duráveis gerado pelo processo manufatureiro de fabricação, que ainda era aquém do propósito de padronização total, era a busca das pequenas produções ou artesãos cooperados. Vender por catálogos, exemplo inovador no século XIX, exigia rigoroso padrão entre produtos. Quase no século XX,

\footnotetext{
Trajetórias em São Paulo - SP e Porto Alegre - RS. Curitiba: UFPR, 2014. Dissertação (Mestrado) Programa de PósGraduação em Design UFPR. Curitiba, 2014.

4 Luthier é o termo em francês, e utilizado no Brasil, que denomina os profissionais que constroem e realizam manutenção em instrumentos musicais.
} 
os mestres começaram gradualmente a introduzir máquinas nas oficinas, principalmente como meio de empregar mão-de-obra menos qualificada, e consequentemente mais barata.

Este processo de mudança também envolveu uma questão social importante para o momento. Cardoso (2011) articula que não existe mais necessidade de se contratar artesãos habilitados. Um designer para gerar o projeto, um gerente para supervisionar a produção e um grande número de funcionários com pouca qualificação para executar as etapas, de preferência como meros operadores de máquinas, seriam suficientes. Aqui os altos salários eram direito apenas para os dois primeiros, ficando o operário em escalas de renda menores. Forty (2007) concorda quando diz que na Revolução Industrial era "desnecessário que os artesãos tivessem talento para o Design, uma vez que tudo que a produção fabril exigia deles era a capacidade de executar os Designs que recebiam".

Willem (1990) considera ser o Design a expressão de uma habilidade humana inata, uma habilidade de mudar o ambiente, presumivelmente para melhor. O autor avalia a imprescindibilidade da capacidade em Design na sobrevivência do homem, desenvolvendo, desde os tempos mais remotos, roupas, ferramentas e equipamentos para a caça. Para Willem (1990), humanos são designers e propõe uma sistematização onde o Design "começa com a percepção de uma necessidade e, se a atividade for bem-sucedida, conclui com o desenvolvimento de uma forma eficaz de satisfazer essa necessidade". Perceber e depois buscar uma forma de satisfazer o que foi percebido.

Cardoso (2005) defende, utilizando-se de uma análise de materiais gráficos brasileiros, a obviedade da atividade Design por não designers. Do mesmo modo, Forty (2007) concorda quando constata que, já no século XVIII, surge a figura do designer, profissional essencial na Revolução Industrial quase cem anos antes do aparecimento do próprio termo design.

Os autores discutidos, nos embasam a considerar aqui o Design como uma atividade inerente ao ser humano, essencialmente quando tratada no âmbito da criação, projeto e produção de artefatos e que participa ativamente do sucesso (ou fracasso) de se fabricar em larga escala.

Como forma de exemplificar como esses cenários sobre o Design se entrelaçam com a Luteria, e podem ser discutidos no âmbito da construção e guitarras elétricas, expomos aqui algumas características que inserem o instrumento direto no contexto de produção, desde sua invenção.

Entre eles, Interesses como produção em série, formas simples de usinagem e utilização de insumos de fácil aquisição, marcaram o início da indústria de guitarras elétricas e se perduram até os dias atuais, absorvendo cada vez mais a tecnologia disponível Donahue (2002) considera que a produção de uma fábrica asiática gera entre oito e quinze mil unidades mensais. A guitarra ganhou seu espaço como um artefato industrial. Além da projetação focada na produção e economia de material, buscava velocidade e eficiência de distribuição. A meta da produção era reprodutibilidade e padronização, a baixo custo. Duchossoir (1991) afirma que a intenção de Leo Fender, como exemplo, era fazer as coisas mais práticas e simples quanto possíveis, com objetivos direcionados para a industrialização. 
Assim, como produto, a guitarra de Fender mostrou exemplos claros do foco na produção. Como exemplo, consideramos inicialmente suas considerações a respeito dos braços construídos em uma única peça de madeira e parafusados ao corpo. Este aspecto facilitava construção e o acabamento, além de aumentar a velocidade e economia de fabricação (Duchossoir, 1991). Ainda que usasse madeiras mais resistentes, "em geral seria menos caro para construir e substituir" (Duchossoir, 1991).

Até Leo Fender, a fabricação de instrumentos ascendentes morfologicamente semelhantes à guitarra seguia modelos desenvolvidos pela indústria, artesanal ou não, do violão e similares, vigente na Luteria desde o começo do segundo milênio. A escala sobreposta ao braço do instrumento se localiza como padrão de produção desde os alaúdes medievais, como forma de aumentar a resistência ao desgaste, numa região do instrumento que sofre atrito constante com os dedos do músico, pela utilização de uma madeira densa e dura. Além do fortalecimento estrutural do braço. Siminoff (2002) considera que a escala deve ser resistente suficiente para a abrasão sofrida por unhas e cordas, além de segurar os trastes em seu lugar e resistir à alta pressão para a colocação destes.

A utilização de escalas confeccionadas em maples (Acer spp), espécie madeireira clara e de menos densa que as tradicionais normalmente escolhidas, é comum em guitarras elétricas desde sua inicial inserção por Leo Fender, se tornando um dos parâmetros para esse instrumento. Mas Leo Fender não só aderia à utilização de maples nas escalas, mas concebeu sua produção para gerar braços e escalas, juntos, em uma única peça de madeira. A questão à qual aqui me atenho, que coloca Leo Fender dentro das atribuições do Design discutidas, é: não se optou por essa madeira e modo de construir por razões estéticas, tonais ou mesmo mecânicas. Seu objetivo era economia de tempo e materiais, enfocada na facilidade de se produzir e no aumento da produção.

O braço já era fabricado com maples em outros instrumentos, assim como, em alguns casos, a escala. O que Leo Fender iniciou foi construção das duas partes em uma só peça. Do mesmo modo, o braço parafusado foi uma alteração positiva no intuito produtivo da guitarra. Diferente do braço colado (ao corpo) dos violões, o braço parafusado permite ajustes fáceis e rápidos, bem como a imediata substituição em caso de defeitos. Além disso, em uma linha de produção, o manuseio de partes separadas torna o processo mais seguro e eficaz.

Em outra forma de diminuir custos em seus processos e conseguir fornecimento suficiente de matéria-prima, bem como equidade na qualidade, Leo Fender trocou as madeiras do instrumento, de acordo com suas necessidades de produção. Essa alteração ocorreu exatamente na facilitação do acesso a insumos e padronização das guitarras. 0 intento resultou, basicamente, na substituição da madeira Ash (Fraxinus americana) (figura 7), com desenhos rajados e muito figurada, para o Alder (Alnus rubra) (figura 8), madeira comum, encontrada nos Estados Unidos da América em larga escala e com uniformidade na tonalidade, o que permitia emendas sem necessidade de tratamento (Duchossoir, 1994).

O tratamento que Duchossoir (1994) sugere é o clareamento, que permite igualar várias peças de madeiras para uma tonalidade muito semelhante, proporcionando assim a possibilidade de uso de duas ou mais partes de madeira em um único corpo de guitarra, quando o instrumento não receberia um acabamento sólido. 
Consideramos essa mudança uma das mais expressivas realizadas por Fender, uma vez que demonstra seu claro enfoque no Design, direcionado à produção. Essa modificação se insere em um assunto controverso da Luteria de guitarras elétricas: a influência da madeira no timbre final do instrumento.

Ainda, pelo ponto de vista de Rayna e Striukova (2011), a economia de escala e foco a produção encontrada por Fender também pode ser ponderada pela simplificação visual. Fender considerava que o que não fosse essencial seria descartável. Ao contrário de outros instrumentos produzidos na mesma época, ricamente ornamentados, a Telecaster ${ }^{\circledR}$ começa a ser produzida lisa, sem detalhes de acabamento, sem incrustações em madrepérola, revestimentos dourados e frisos nas quinas (Rayna e Striukova, 2011).

Importante lembrar que, considerando os textos de Cardoso (2011), "a mecanização dos processos industriais nem sempre acarretavam uma melhoria da qualidade, mas apenas a capacidade de produzir mais quantidade com menos operários". Talvez aqui se encontre um dos motivos para o qual França (2005) sugere a atual valorização do trabalho artesanal. Se tratando de instrumentos musicais, a padronização motivada pela produção em série supriu a necessidade de se alcançar um amplo mercado. Por outro lado, uma parcela dos consumidores encontra qualidades - que não são tratadas neste texto - em instrumentos artesanais. A atual coexistência de indústrias e artesãos na Luteria (Rayna e Striukova, 2011) comprova este evento.

Apesar das questões de industrialização da guitarra no momento de seu início comercial nos Estados Unidos aqui discutidas, é importante sinalizar que a empresa Fender ${ }^{\circledR}$, considerada por nós a precursora norte-americana desta atividade (industrialização), recebe essa qualificação por ter sido a responsável por tornar a guitarra popular, através de uma produção, desde o princípio, em série. Entretanto, a caracterização da Fender ${ }^{\circledR}$ como fábrica não segue exatamente as descrições concebidas pelos autores aqui citados, essencialmente por situar-se em um momento histórico diferente da conceituação proposta. $\mathrm{O}$ ambiente tecnológico de que Fender dispunha nos anos 1950 possibilitava padronização e quantidade, mas em valores muito aquém da capacidade produtiva de uma fábrica atualmente. Millard (2004) comenta sobre a produção da empresa em cerca de duzentos e cinquenta instrumentos por mês e o emprego de aproximadamente vinte funcionários, que operavam máquinas pesadas e trabalhavam artesanalmente apenas quan do necessário (Millard, 2004). Assim, essa pesquisa considera ser a guitarra resultante da indústria fabril, mas nunca desconsiderando o contexto de sua época.

\section{Desenvolvimento e Adaptação Tecnológica na Luteria}

De forma prática, o objetivo da luteria de guitarra é o mesmo entre todos os construtores o artefato guitarra. Entretanto, o modo de fazer, no tanger de sua tecnologia específica, quase sempre se apresenta sob modos diversos e distintos e representam um projeto ${ }^{5}$ escolhido pelo construtor. As técnicas da luteria são, juntamente com os saberes e conhecimentos práticos, elementos essenciais quando se pretende analisar seu processo produtivo e pensar a tecnologia

\footnotetext{
${ }^{5}$ Considera-se aqui a definição de Gilberto Velho (2003), onde projeto se trata de uma seleção dentre opções para se chegar a uma meta, mediada pelo contexto sociocultural.
} 
que intermedia a passagem da concepção ao produto final.

Para a compreensão do conceito de tecnologia aqui referido é necessário um desvencilhamento de sua imagem comumente associada à modernidade, progresso e eficiência. Esse determinismo tecnológico é evidente na historiografia da tecnologia, o qual the cede autonomia a ponto de existir/agir independente das pessoas (EDGERTON, 1999). Este fato se dá pela consideração da tecnologia acontecer independente de relações sociais, "mas sim como técnica, artefato ou máquina" (LIMA FILHO e QUELUZ, 2005, p.14). Assim, em busca de desprendimento dessas concepções, considera-se aqui ser a tecnologia um conjunto de conhecimentos derivados de fontes diversas como técnicas, descobertas e invenções (OLIVEIRA, 2008), que é completado quando da "apropriação de conhecimentos, saberes e práticas pelo ser social" (LIMA FILHO e QUELUZ, 2005, p.4). Queluz e Lima Filho (2005), ainda citam Staudemeier para firmar a importância das pessoas (o ser social) e organizações em um sistema tecnológico como conexão com a política, economia e cultura, que vai além de máquinas e processos produtivos.

Analisando por essa definição, pondera-se, então, ser a tecnologia da luteria o agrupamento das técnicas e métodos particulares da atividade, bem como suas inovações e processos criativos da própria técnica aplicada, envolvendo conhecimentos e saberes e suas aplicações nas práticas e espaços do trabalho, considerando todas essas facetas pelo ponto de vista humano, do construtor, dos funcionários da fábrica, do mercado por onde esse instrumento circula e é mercantilizado.

O processo de desenvolvimento tecnológico na luteria demonstrou uma dinâmica que se moldou durante séculos de uma atividade em constante alteração, uma vez que o ambiente cultural delineava os rumos pelos quais a construção de instrumentos iria caminhar. Conforme explica Bruné (2011, p. 13) as "mudanças na música exigiram que o luthier se atualizasse e passasse a construir novos instrumentos, ou a adaptar os antigos para o novo momento", e dessa forma a tecnologia construtiva também se atualizou, modificando suas estratégias de produção, seja no aumento da produtividade, seja na adaptação a essa nova ambiência.

Considerando essa dinâmica tecnológica para a realidade deste texto (a construção de guitarras no Brasil nos anos 1960 e 1970), as narrativas dos entrevistados mostram que a tecnologia se atualizava e o luthier exercitava sua contínua busca no desenvolvimento de seu trabalho, através de inovações e readequações frequentes. Este acomodamento e ajustes habituais fazem parte do conhecimento do trabalho, na proporção em que necessidades vão surgindo. Dominar o processo produtivo implicava no livre poder de criar e adaptar técnicas, com maior precisão e rendimento. Utiliza-se aqui o comentário de um entrevistado, Alaor Rangon (2013), que exemplifica o argumento: “(...) da ((guitarra)) acústica o corpo era prensado, numa prensa que mandei fazer. Eu era ferramenteiro né, então sabia o que podia ser feito". Este trecho contempla o momento que Alaor Rangon insere uma nova técnica construtiva e específica para a luteria, alterando a tecnologia do seu trabalho, antes realizado em guitarras maciças e se introduzindo na sequência ao instrumento acústico. O entrevistado também comenta que o equipamento desenvolvido - a prensa - era uma técnica específica e exclusiva, que o diferenciava de outros fabricantes: "olha, o que a gente fazia ninguém fazia. Outras empresas tentavam copiar da gente. Queriam saber como a gente fazia. Mas não, isso era só a gente" (RANGON, 2013).

Branco (2005) acredita que a palavra "técnica" envolve todos os métodos e processos aplicados a uma atividade. Este conceito pode ser adotado quando trata objetivamente do processo em si, da forma de fazer; mas necessita e se obriga, como método de pensar os modos produtivos 
de uma atividade, e especificamente no âmbito da luteria, explorar, além do "fazer", como esse processo se aprimora: como o fenômeno técnico é desenvolvido pelos sujeitos construtores de guitarra. Assim, a alteração deste procedimento envolve conhecimentos particulares. Como o "jeito de fazer" é percebido pelo construtor de guitarra, define seu trabalho em questões de produtividade e qualidade: "Mas não era pelo dinheiro, mas pelo jeito de fazer. Não dá pra fazer na mão ((sobre o tampo curvado)). E a prensa resolvia bem rápido" (RANGON, 2013). Esse desenvolvimento é presente nas narrativas dos entrevistados em diversos momentos e se mostra como um indicativo de progresso (buscando produtividade) do trabalho. Sendo elaborados pelos próprios construtores, ou aplicados sobre técnicas inspiradas em terceiros (técnicas aprendidas), é esse desenvolvimento que vai definir o êxito destes indivíduos como construtores de guitarra, além de promover um aprendizado empírico, característico da luteria.

Uma das evidentes características da tecnologia da construção de guitarras é a adaptação de equipamentos comuns ao processo construtivo, resultando, a cada momento, em uma nova técnica desta atividade. Pequenos motores (máquina de costura ou toca-discos) tinham sua função ajustada ao enrolamento de bobinas da captação magnética, além de envolver ganho de produtividade. Esse equipamento é citado pelos entrevistados de maneira ordinária e generalizada, evidenciando ser um item básico para sua produção, além de gerador de um diferencial, uma vez que construindo seus próprios captadores, os luthiers tinham controle sobre seu resultado funcional final.

Outra máquina específica construída que também pode ser considerada uma adaptação tecnológica para aumento de produtividade e qualidade, pois permitia precisão e maior velocidade no processo, foram os sistemas de cortar as cavidades que recebem os trastes. Romeu Benvenuti (2013) descreve basicamente o trabalho deste equipamento: “Depois, a gente tinha a maquininha, uma serrinha pequeninha. Uma serra circular bem fininha e já com o carrinho que andava. Você tem o molde, vai pulando né" (BENVENUTI, 2013).

Além de adaptações para um processo produtivo específico para guitarras os entrevistados, em diversos momentos, se encontraram em posições de deficiência técnica, seja por escassez de equipamentos e máquinas adequados ou por objetivos de incremento de produção, com benéficos qualitativos e quantitativos. Assim, através do desenvolvimento empírico, se viam na inevitável necessidade de construir seu próprio ferramental, não só desenvolvendo formas de se produzir, mas criando maquinário apropriado às conveniências. O êxito buscado se dirige diretamente às suas possibilidades de produzir mais, mais rápido e com maior qualidade. Ante a necessidade mais básica do trabalho com madeira - a usinagem, possuir uma máquina realizando a etapa inicial do processo significava velocidade e precisão, bem como a chance se inserir e permanecer competitivo no mercado. A serra circular produz cortes retos e permite ao construtor reproduzir várias vezes a mesma medida, sendo de intenso uso na produção em série, mas nem sempre estava disponível aos construtores em seus inícios de carreira. Para exemplificar, é possível considerar a fala de Sebastião Machado da Silva: "aí o que fizemos? Compramos um motor. Tinha uma valeta no meio, de mais ou menos meio metro. Colocamos o motor lá. Esse girava todas as máquinas. Começamos assim. Olha só..." (SILVA, 2012). O comentário de Sebastião demonstra uma dificuldade da qual participou e que, sem criatividade e uma adaptação técnica, poderia ter se tornado um empecilho ao seu negócio. Além disso, o relato deste fato, lembrança de um momento de contratempos, reafirma convicções da necessidade da inventividade técnica nesta atividade.

Vale ressaltar que nem sempre o saber de técnicas específicas era propriedade do 
luthier/proprietário da empresa. Ao contrário, a divisão de trabalho em suas empresas, quando existia, possibilitou um incremento técnico que provavelmente não seria experimentado se tivessem se mantido na produção individual artesanal. A reunião de profissionais de áreas diversas, convenientes para a luteria, mas independentes como atividade, possibilitou um agrupamento de técnicas e, mais relevante ainda também contribuiu para o desenvolvimento técnico e específico para a construção de guitarras. A composição de trabalhadores marceneiros, ferramenteiros, técnicos em eletrônica e pintores levou inovação e originalidade para a produção, no âmbito dos entrevistados, fato que demonstra um caráter híbrido da luteria, além da construção social das técnicas nesta atividade. Múltiplos foram os incrementos técnicos agregados aos processos produtivos pelos funcionários (participantes terceiros em geral) na tecnologia da luteria. Máquinas particulares, alternativas para procedimentos, processos rápidos e econômicos e exclusividade. Romeu Benvenuti (2013) mostra a evidente importância da participação de um marceneiro no desenvolvimento de uma técnica específica, quando comenta: "esse marceneiro, ele fez... ...ele juntou três serras (...) A ferramenta que ele criou, ele que mexia. Então ele fazia um canal e fazia o outro canal. Encaixava direitinho" (BENVENUTI, 2013). Esse comentário diz respeito a uma ferramenta própria para cortar canais no braço da guitarra, uma máquina própria e singular. Essa construção social da tecnologia é abordada por Pinch e Bijker (1987), onde argumentam ser a tecnologia (ou o próprio artefato gerado) uma indução social, composta com a participação de diversos agentes com interesses semelhantes, ao contrário do conceito linear que considera a tecnologia como resultado de um processo autônomo. Além dos envolvidos diretamente no processo produtivo, variados agentes participavam diretamente desta construção social. Cabe aqui também citar o mercado consumidor como um importante definidor da produção, influenciando formas, modelos, cores, tamanhos, e consequentemente os métodos construtivos, os quais requeriam adequação para atender demandas específicas.

Mesmo tratando-se de exemplos, são fatos que mostram uma realidade da luteria brasileira, especificamente a de guitarras nos anos 1960 e 1970, com uma atividade dinâmica já a partir da concepção e adaptação de técnicas e do modo de "fazer". Constituir-se luthier de guitarras no período analisado carregava consigo uma inevitável demanda por inventividade e desenvolvimento de tecnologias próprias e adequadas.

\section{Considerações}

Este texto, sendo um excerto de dissertação, considera apenas uma parte das trajetórias laborais narradas pelos colaboradores mas, ainda que de forma heterogênea e concisa, mostra como os desdobramentos do trabalho dos entrevistados na luteria se calçaram no domínio e transformação de técnicas, específicas ou não, e direcionadas a tecnologia singular da construção de guitarras. Pretendemos expor uma reflexão sobre como se desenvolveu a tecnologia do fazer de cada luthier, que se desenrolou como principal ação intermediadora entre a concepção e o artefato gerado, uma vez que remetem diretamente à produção, envolvendo conhecimentos e práticas da atividade.

Também é possível observar que o estudo das técnicas explicita como as relações humanas e materiais se davam, que caracteriza, ainda que inicialmente, a tecnologia da luteria de guitarras no Brasil e mostra formas pelas quais o desenvolvimento tecnológico pode acontecer, os saberes participantes e como essas relações vão compondo uma base para etapas seguintes e futuras. 
Assim, por meio dessa discussão, objetivamos mostrar que o desenvolvimento tecnológico é dinâmico, diversificado, multifacetado, criativo, repleto de adaptações e não se dá apenas no ambiente acadêmico, mas acontece em oficinas, ateliês, estúdios; em uma mescla de técnicas e conhecimentos, de construção conjunta de saberes e desenvolvimento contínuo.

No começo era interessante porque a criatividade fazia você se virar. Então as ferramentas eram tudo... (BENVENUTI, 2013)

\section{Referências}

ALMEIDA, Gislleine Marques e PIRES, Maria Alzira. A Arte da Luteria no Brasil. Revista Educação, v.7, $\mathrm{n}^{\circ} 1, .2012$.

BENVENUTI, Romeu. Entrevista: depoimento [jul. 2012]. Entrevistador: PEREIRA, Rodrigo Mateus. São Paulo, 2012. Entrevista concedida para a dissertação de mestrado de Rodrigo Mateus Pereira.

BRANCO, Anselmo Lázaro. Técnica e Tecnologia: Como o Homem Construiu o Conhecimento [Internet]. São Paulo: UOL Educação, 31 de julho de 2005 [acesso em 21 de setembro de 2012]. Disponível em: http://educacao.uol.com.br/disciplinas/geografia/tecnica-e-tecnologia-como-ohomemconstruiu-o-conhecimento.htm.

BRUNÉ, R.E. Lutherie: Yesterday, Today and Tomorrow. American Lutherie: The Quartetly Journal of the Guild of American Luthiers, Estados Unidos da América, n 107, vol. 3, 2011.

CAESAR, Wesley. Guitar Book: o Guia da Guitarra. São Paulo: Editora TKT, 1999.

EDGERTON, David. From Innovation to Use: Ten Ecletic Theses on the History of Technology. History and Technology, vol. 16, 1999.

CARDOSO, Rafael (org.). O Design Brasileiro Antes do Design: Aspectos da História Gráfica, 1870-1960. São Paulo: Cosac Naify, 2005.

CARDOSO, Rafael. Uma Introdução à História do Design. 3ạ Ed. São Paulo: Blucher, 2011.

DONAHUE, James. Guitars: Design, Production and Repair. Pennsylvania: Noah James Publishing, 2002.

DUCHOSSOIR, A.R. The Fender Telecaster: the Detailed Story of America's Senior Solid Body Electric Guitar. Milwaukee: Hal Leonard Publishing Corporation. 1991.

. The Fender Stratocaster. Milwaukee: Hal Leonard Publishing Corporation,

1994.

EVANS, Tom e Mary Anne. Guitars: From the Renaissance to Rock. Londres: Paddington Press, 1977. FORTY, Adrian. Objetos de Desejo: Design e Sociedade desde 1750. São Paulo: Cosac Naify, 2007.

FRANÇA, Rosa Alice. Design e Artesanato: uma Proposta Social. Revista Design em Foco, v.02, n. 02, jul.-dez. 2005. Universidade do Estado da Bahia, Brasil.

LIMA FILHO, Domingos e QUELUZ, Gilson. A Tecnologia e a Educação tecnológica: Elementos para uma sistematização conceitual. In: Educação e Tecnologia, Belo Horizonte: CEFET-MG, v. 10, n.1, 
2005.

MARTINS, Adão Oliveira. Entrevista: depoimento [abr. 2013]. Entrevistador: PEREIRA, Rodrigo Mateus. Porto Alegre, 2013. Entrevista concedida para a dissertação de mestrado de Rodrigo Mateus Pereira.

MILLARD, André. The Electric Guitar: a History of an American Icon. Baltimore: The John Hopkins University Press, 2004.

OLIVEIRA, Eva Aparecida. A Técnica, a Techné e a Tecnologia. Revista Eletrônica do Curso de Pegadogia do Campus Jataí - UFG, v. 02, n. 05, jul./dez. 2008.

PINCH, Trevor e BIJKER, Wiebe. The Social Construction of Facts and Artifacts: Or How the Sociology of Science and the Sociology of Technology Might Benefit Each Other. In: PINCH, Trevor, BIJKER, Wiebe e HUGHES, Thomas (Ed). The Social Construction of Technological Systems: New Directions in the Sociology and History of Technology. Cambridge: MIT Press, 1987.

RAYNA, Thierry e STRIUKOVA, Ludmila. Engineering vs. craftsmanship: Innovation in the electric guitar industry (1945-1984). In: ROBERTSON, Paul L. e JACOBSON, David. Knowledge Transfer and Technology Diffusion. Edward Elgar Publish: Inglaterra. 2011.

RANGON, Alaor Ciro. Entrevista: depoimento [abr. 2013]. Entrevistador: PEREIRA, Rodrigo Mateus. São Paulo, 2013. Entrevista concedida para a dissertação de mestrado de Rodrigo Mateus Pereira.

ROQUE, Carlos. Luthiers: Artesãos Musicais Brasileiros. São Paulo: Edição do Autor, 2003.

SILVA, Sebastião Machado. Entrevista: depoimento [jul. 2012]. Entrevistador: PEREIRA, Rodrigo Mateus. São Paulo, 2012. Entrevista concedida para a dissertação de mestrado de Rodrigo Mateus Pereira.

SIMINOFF, Roger. The Luthier's Handbook: a Guide to Building Great Tone in Acoustic Stringed Instruments. Milwaukee: Hal Leonard Corporation, 2002.

WAKSMAN, Steve. Instruments of Desire: The Electric Guitar and Shape of Musical Experience. Cambridge: Harvard University Press, 2001.

WILLEM, Raymond. Design and Science. Design Studies, v.11, n.1, janeiro. 1990. Atlanta, Estados Unidos da América. 